\title{
2009 Annual Health Physics Report for the HEU Transparency Program
}

\author{
Radoslav Radev
}

Lawrence Livermore National Laboratory

This work is performed under the auspices of the U.S. Department of Energy by Lawrence Livermore National Laboratory under Contract DE-AC52-07NA27344 
This document was prepared as an account of work sponsored by an agency of the United States government. Neither the United States government nor Lawrence Livermore National Security, LLC, nor any of their employees makes any warranty, expressed or implied, or assumes any legal liability or responsibility for the accuracy, completeness, or usefulness of any information, apparatus, product, or process disclosed, or represents that its use would not infringe privately owned rights. Reference herein to any specific commercial product, process, or service by trade name, trademark, manufacturer, or otherwise does not necessarily constitute or imply its endorsement, recommendation, or favoring by the United States government or Lawrence Livermore National Security, LLC. The views and opinions of authors expressed herein do not necessarily state or reflect those of the United States government or Lawrence Livermore National Security, LLC, and shall not be used for advertising or product endorsement purposes.

This work performed under the auspices of the U.S. Department of Energy by Lawrence Livermore National Laboratory under Contract DE-AC52-07NA27344. 


\section{Table of Contents}

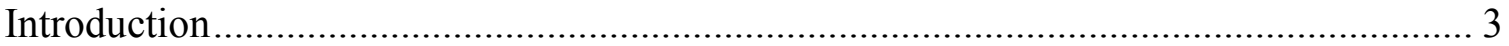

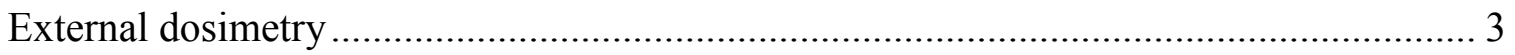

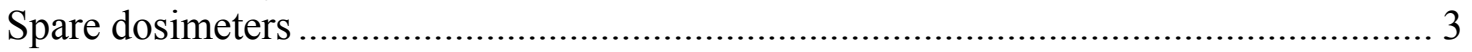

Dose information from the Russian dosimeters ............................................... 3

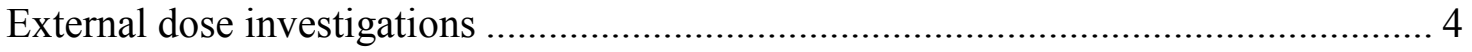

Logistics and dose reporting .......................................................................... 4

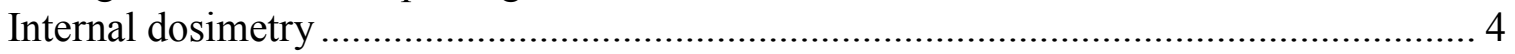

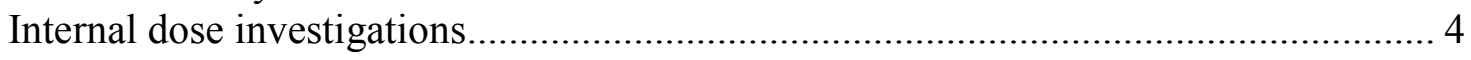

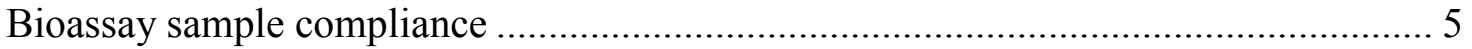

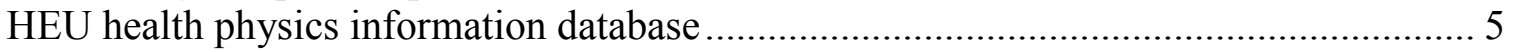

2009 Radiological data from the Russian plants....................................................... 5

Health physics support of the BDMS activities .......................................................... 6

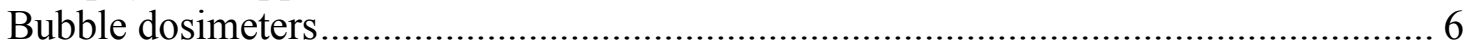

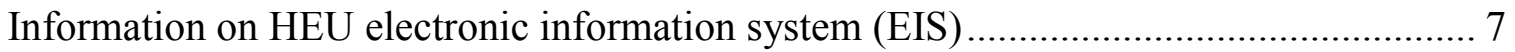

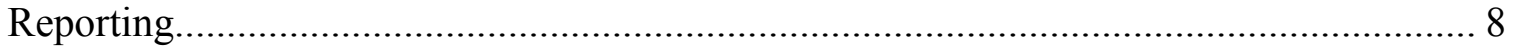

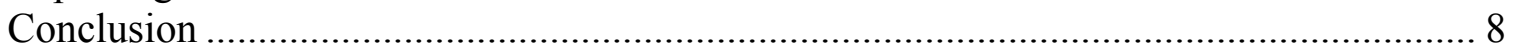

Appendix A - 2009 Bioassay sample compliance....................................................... 9

Appendix B - 2009 Russian plants radiological data charts .......................................... 11 


\section{Introduction}

During the 2009 calendar year, Lawrence Livermore National Laboratory (LLNL) provided health physics support for the Highly Enriched Uranium (HEU) Transparency Program for external and internal radiation protection. LLNL also provided technical expertise related to BDMS radioactive sources and Russian radiation safety regulatory compliance. For the calendar year 2009, there were 159 person-trips that required dose monitoring of the U.S. monitors. Of the 159 person-trips, 149 person-trips were SMVs and 10 person-trips were Transparency Monitoring Office (TMO) trips. There were 4 monitoring visits by TMO monitors to facilities other than UEIE and 10 to UEIE itself. LLNL's Hazard Control Department laboratories provided the dosimetry services for the HEU Transparency monitors.

\section{External dosimetry}

LLNL provided 618 TLD dosimeters in 2009 for monitoring potential external dose:290 personal dosimeters, 232 control dosimeters and 96 spares to Pragma in Yekaterinburg and TMC in Moscow. Approximately half of the dosimeters supplied were returned and were not read. This includes the unused spare dosimeters from Yekaterinburg and Moscow and both the personal and control arbitration TLDs left in Russia until a post trip dose letter is provided. However, both read and unread TLDs needed to be zeroed and re-calibrated before subsequent use.

Spare dosimeters

In 2009, all HEU Transparency monitors went on assignments in Russia with a complete set of personal and control dosimeters. In order to avoid a failure of a trip mission due to lost dosimeters at customs, a pool of 24 spare dosimeters was maintained at TMC in Moscow, in addition to the 24 spare TLDs at the Pragma office. The current number of spare dosimeters allows replacing the loss of all dosimeters of one single team. In such case the spare dosimeters will be replenished by the next team. In normal situations the spare dosimeters are exchanged semi-annually.

\section{Dose information from the Russian dosimeters}

The dose readings from the Russian TLDs (dosimeters) compare well within the statistical uncertainties with the readings from the U.S. dosimeters. The information from the Russian TLDs together with the arbitration TLDs (monitor's second U.S. dosimeter) is instrumental in resolving discrepancies and anomalies in the readings of the primary U.S. dosimeter. In 2009 we received the external dose readings from the Russian TLDs supplied to the U.S. monitors by the plants as follows:

- $\mathrm{SChE}$ - for all SMVs and all monitors

- $\mathrm{MPA}$ - for all SMVs and all monitors

- ECP - for all SMVs and all monitors

- UEIE - none 


\section{External dose investigations}

There have been 6 external dose investigations in 2009 which resulted in assigning an insignificant dose to two monitors. The other investigations resulted in zero dose assignments. For any dosimeter reading above $10 \mathrm{mrem}$, the arbitration TLD was analyzed together with the reported dose from the Russian TLD, when available, in order to evaluate if the monitor has/has not received an occupational dose from the HEU assignment in Russia. The arbitration and Russian TLDs, the radiological data we receive from the plants and personal interviews are used to resolve radiation exposure investigations.

No other external dose concerns were raised during the 2009 calendar year.

\section{Logistics and dose reporting}

Customs letters for both the U.S. and Russian customs were included in the dosimeters packages for each trip to facilitate customs inspections. LLNL retrieved all 2009 arbitration dosimeters from the monitored Russian nuclear facilities. In 2009 LLNL provided DOE's HEU Transparency Program management with post trip dose reports after each trip. All HEU monitors, but two, received zero doses from external radiation exposure in 2009. The two positive external doses were at the recording limit and well below the U.S. and the Russian regulatory limits for occupational and general public exposure.

\section{Internal dosimetry}

A total of 149 bioassay samples were submitted in 2009: 145 post-trip (for uranium) and 4 baseline samples ( 2 for uranium and 2 for plutonium). All HEU Transparency monitors who participated in assignments in Russian uranium processing facilities have provided baseline bioassay samples. All post trip bioassay samples from the 2009 calendar year were analyzed and no internal dose was assigned to any monitor in 2009.

\section{Internal dose investigations}

One post trip bioassay sample showed results slightly above the investigation level. The investigation concluded that no credible uranium uptake and internal dose can be attributed to this individual based on the HEU assignment.

There were no other internal dose concerns.

The internal dose is assigned based on the bioassay result (content of uranium compounds in urine), appropriate biokinetic models, chemical and physical form of uranium compounds, and other pertinent information. The minimum detectable internal dose (MDD) from uranium bioassays depends on several factors, two of which are the chemical and physical form of the uranium compound and the time elapsed between a potential uranium intake and the time the bioassay sample was provided. We can not control the first parameter, however we can try to shorten the time the bioassay sample is collected by obtaining it as close as possible to the day of the return to the USA. This allows lower uranium intakes and doses to be detected and will improve the reliability of the internal dose assessment. 
Bioassay sample compliance

The established bioassay procedure requires each monitor to provide a post trip bioassay sample within 3 days of arrival in the USA. For 2009 calendar year, $92 \%$ of the samples were in compliance with this requirement, with the average time interval between the arrival of the monitors in the USA and the providing of the post trip bioassay sample being 1.6 days. Only 3 monitors have provided bioassay sample more than 10 days after their return to the U.S.A. There were 4 monitors that had other assignments following the HEU trip and did not return immediately to the U.S.A. to provide bioassay sample. If these 4 monitors are excluded, the bioassay sample compliance would be $95 \%$. Appendix A of this report has charts providing information on the bioassay sample compliance for 2009 calendar year.

In 2009, LLNL provided the HEU Transparency Program management with quarterly internal dose reports (bioassay reports) containing information on the internal dose, the baseline bioassays, the procedure compliance and the status of bioassay samples received, analyzed and in process of being analyzed.

\section{HEU health physics information database}

LLNL maintains a confidential database to support the reporting of HEU radiation protection data. Official dosimetry data are stored in the LLNL's Hazard Control Department database. The HEU database contains historical external and internal dose information for every HEU Transparency monitor, as well as specific information for each trip, TLDs supplied, returned or left in Russia, baseline bioassays, submitted signed exposure release forms and monitor's data. The health physics database is essential for generating the post trip and the annual dose reports, as well as for any future inquiries. In order to comply with the provisions of the Privacy Act of 1984, we have obtained and keep on file signed Radiation Exposure Release forms for all HEU Transparency monitors that had assignments in the calendar year 2009.

The individual annual occupational dose information for each monitor for 2009, detailing the total dose as well as the external and internal doses from each monitoring assignment, was mailed to each monitor in January 2010.

\section{Radiological data from the Russian plants}

At the end of 2009 the HEU health physicist obtained the revised Russian Federation radiation safety regulation "Radiation Safety Norms NRB-99/2009 SanPin 2.6.1...09". The Russian regulatory practice is to review and revise if necessary every 10 years these federal radiation safety regulations. The federal allowable radiation levels of concern to BDMS operation and U.S. monitoring activities have not changed. The revised NRB99/2009 are not expected to affect the HEU and BDMS monitoring activities.

The 2009 radiological data, received from the Russian uranium processing plants under the HEU agreement, indicate that there are no radiological concerns for the U.S. monitors working in Russia who follow the work and personnel protection guidelines. 
The plant radiological data include gamma exposure rates, airborne and removable surface contamination levels in the areas visited by the U.S. monitors. These data supplement the information from the U.S. dosimeters and the bioassay sample analysis. The HEU Transparency Agreement Annexes have provisions that the radiological environment data for the areas of the Russian plants visited by the U.S. monitors, be provided to the U.S. However, they do not specify what data, in what format, for what time intervals, or any other details. For example, a provision for sharing contamination or radiological accident data affecting the U.S. monitors is not specified in the HEU Transparency Agreement documents.

In 2009 we received the following radiological data from the plants:

- $\quad$ ECP - gamma exposure rates, surface alpha contamination, and airborne alpha contamination for each day of the SMV and for all SMVs;

- MPA - gamma exposure rates, surface alpha contamination, and airborne alpha contamination for each day of the SMV and for all SMVs;

- SChE -gamma exposure rates, surface alpha contamination, and airborne alpha contamination averaged for the 4 days of each SMV;

- UEIE -gamma exposure rates, surface alpha contamination, airborne alpha contamination, and neutron dose rates at the BDMS room averaged over a one-month period with June-July-August averaged together (we did not receive data for December since no U.S. monitors were present at UEIE).

The graphs in Appendix B (Appendix B is a separate C/FGI-MOD document) provide the gamma exposure levels and the airborne and surface contamination at the monitoring points and guiding action levels for each of the plants in 2009. A short discussion of the 2009 radiological data from the plants is included in Appendix B.

Detailed plant radiological data along with the action levels and the recommended precautions are included in each trip's Team Instructions Book.

\section{Health physics support of the BDMS activities}

\section{BDMS sources specifications}

LLNL provided assistance in developing the source specifications and ordering stronger sources which will allow longer intervals between source change campaigns. The specifications were developed in a manner to maximize the output and the reliability of the BDMS measurements and, at the same time, to comply with the Russian Federation radiation safety regulatory limits. The specifics of the dose rate measurement instrumentation and treatment of measurement errors were taken into account in the development of the source specifications. The BDMS source specifications were used as a basis for the April 2009 Prague negotiations on reducing the transparency measures.

\section{Bubble dosimeters}

During CY 2009 LLNL health physicist discussed and agreed with the radiation safety professionals at all three plants on the numbers of bubble dosimeters needed to support the installation of stronger sources. The currently mutually agreed numbers of bubble 
dosimeters for the source replacements in 2010 are shown in Table 1. The bubble dosimeter information is valuable for the U.S. monitors and the Russian personnel as an immediate indication in case of a significant neutron exposure or radiation leakage from the BDMS shielding.

Table 1 - Current status of the number of bubble dosimeters

\begin{tabular}{|l|c|}
\hline & Cf-252 and Co-57 source changes in 2010 \\
\hline UEIE & 20 \\
\hline ECP & 20 \\
\hline SChE & 20 \\
\hline
\end{tabular}

\section{Information on HEU electronic information system (EIS)}

The available data on EIS in the BDMS directory include two folders - BDMS Sources and Bubble Dosimeters for the use of the HEU community.

The BDMS Sources folder contains:

- All current and past Cf-252, Co-57 and Am-241 passports for UEIE, ECP and SChE BDMS sources

- Co-57, Am-241, and Cf-252 source specifications

- All radiation safety reports for the source change activities in English and the Russian originals for UEIE, ECP and SChE

- Tables of the detailed dose rate (gamma+neutron) measurements around the BDMS FM and EM units at UEIE, ECP and SChE for regulatory compliance

- Tables of the relative californium source measurements of the new, old, and the reference sources with any pertinent information for source changes and installations at the three plants

- Tables of the Cf-252, Co-57, and Am-241 source positions at UEIE, ECP, and SChE

The bubble dosimeter folder on EIS contains:

- Test results from the 2002 and 2008 certification of the bubble dosimeters by Doza (in Russian)

- 2003 and 2008 Bubble Dosimeter Accreditation certificate - original in Russian and the English translation

- Accreditation testing report and description - in Russian and in English 


\section{Reporting}

In 2009 LLNL provided the following reports related to the health physics issues of the HEU Transparency Program activities:

- Post trip dose reports after each trip

- Quarterly bioassay (internal dosimetry) reports

- 2008 Annual Health Physics Report for the HEU Transparency Program

- 2008 Annual Occupational Dose Reports to each monitor that had a trip to Russia

- 2008 Annual Occupational Dose Reports to the POC for all monitors in his area

- Reports on various health physics topics requested by the HEU Transparency Program management

\section{Conclusion}

In 2009, the HEU Transparency activities in Russia were conducted in a radiologically safe manner for the HEU Transparency monitors in accordance with the expectations of the HEU Transparency staff, NNSA and DOE. The HEU Transparency Program now has over fifteen years of successful experience in developing and providing health and safety support in meeting its technical objectives. 


\section{Appendix A - 2009 Bioassay sample compliance}

Figure 1. Bioassay compliance chart including all monitors in 2009

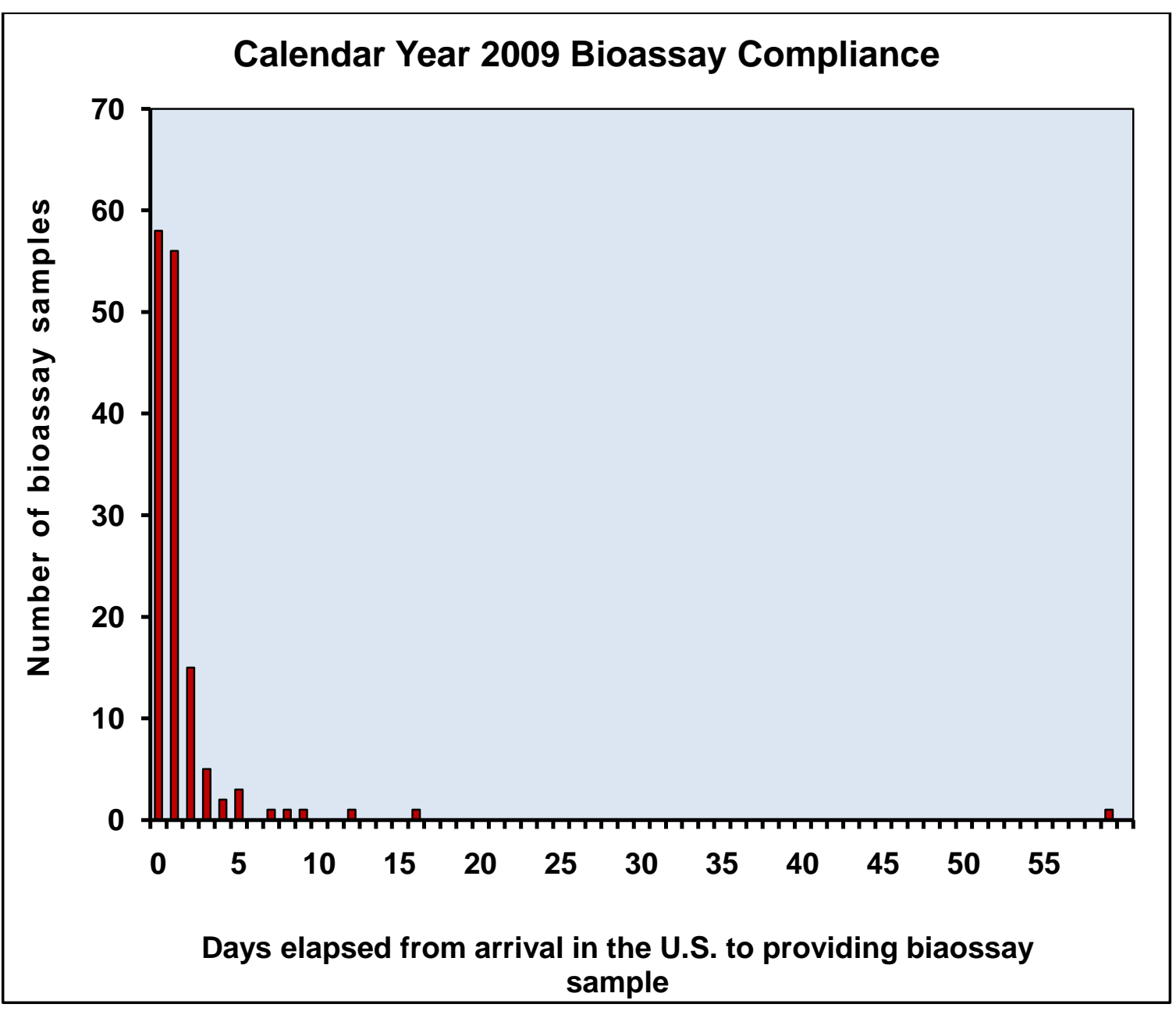


Figure 2. Bioassay compliance chart excluding the latest (59 days) sample

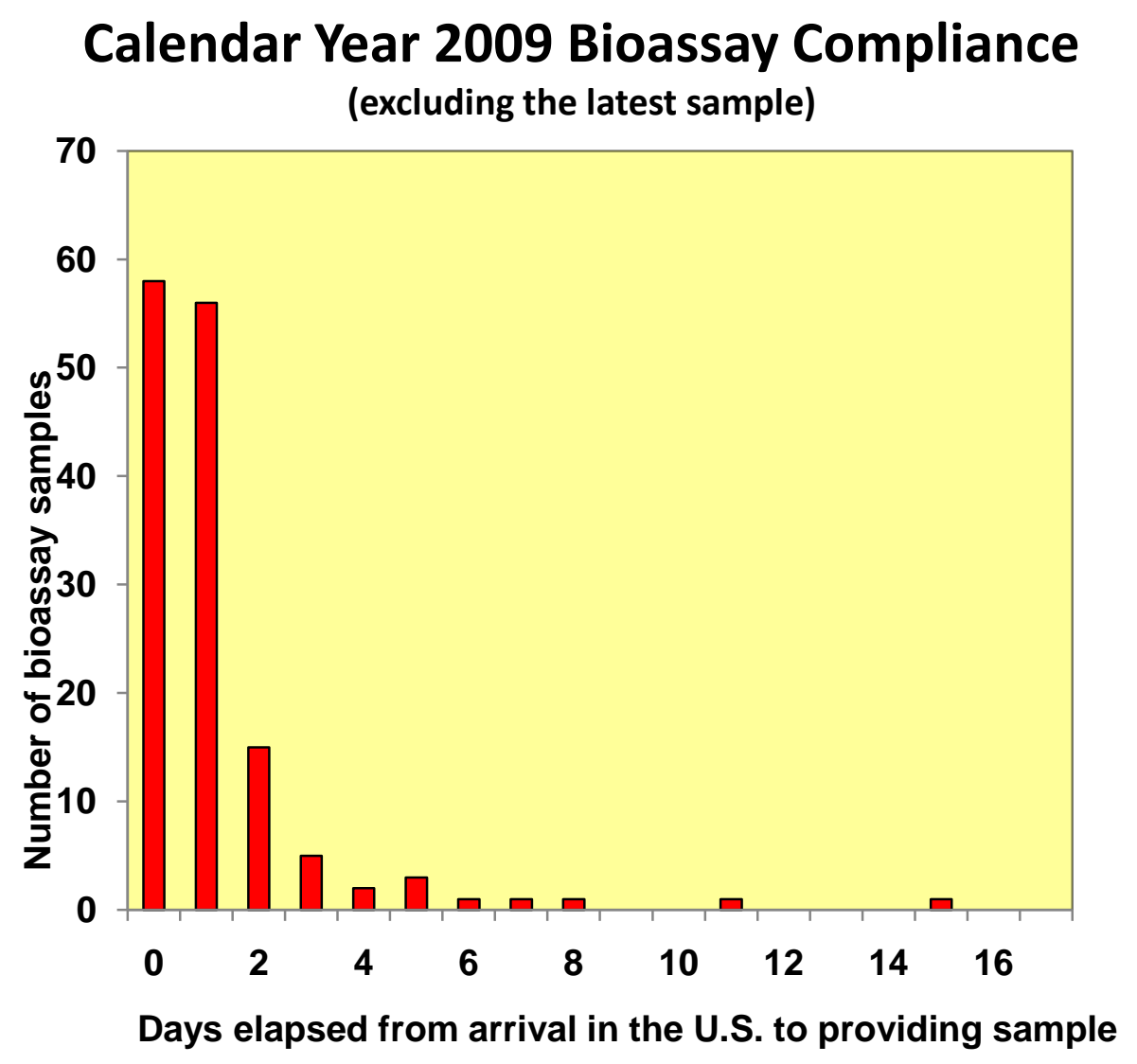


Appendix B - 2009 Russian plants radiological data charts

Appendix B is a separate document that is marked C/FGI-MOD 